\title{
Some Benefits of Extracurricular Reading in Foreign Language Teaching
}

\author{
M.V. Kuimova ${ }^{1}$, S.A. Ukhov ${ }^{l}$ \\ ${ }^{1}$ National Research Tomsk Polytechnic University, Tomsk, Russia \\ mkuimova@mail.ru
}

\begin{abstract}
Reading is one of the major sources of information and knowledge. It is an essential element to succeed in the fast-moving world of today and tomorrow. Extracurricular reading in the target language complements academic subjects and develops a well-rounded, socially skilled, empathic and independent student. It empowers students with a high level of information culture, makes them able to interpret, analyze and systematize the obtained information. The article studies the role of extracurricular reading in foreign language teaching, offers criteria for the text selection and exercises to work with texts, and presents the positive results of introducing extracurricular reading to the development of foreign language skills.
\end{abstract}

Keywords: communicative competence; extracurricular reading; foreign language competence; foreign language teaching; information culture.

Reading is a basic tool in the living of a good life. Joseph Addison

\section{Introduction}

Extracurricular activities are important in students' training. They allow students to meet new friends, spend time with their peers outside the classroom, and explore and pursue their interests. They favor higher grades, form a positive attitude towards the university experience and arm students with many skills that future employers are looking for in university graduates: communication, teamwork skills, time-management skills, ability to prioritize and hold long-term goals. Extracurricular activities are generally available for everybody who wants to participate, particularly when organized at a convenient time for students and teachers. They can be in the form of meetings, clubs, special interest circles, educational walks, trips, excursions, etc.

In foreign language teaching, extracurricular work facilitates the expansion and deepening of language skills, encourages the study of history, culture and literature of the target language countries. Moreover, it contributes to the development of:

- social and cognitive motives of educational activity;

- communication and language skills;

- students' horizons and erudition;

- character, creativity and spirit.

\section{Background literature}

In a reduced number of foreign language classes, extracurricular reading offers additional opportunities for teaching and developing of students' foreign language skills. Students benefit from confronting the challenge of language that is slightly beyond their independent level [Chen, 2014; Kuimova, Burleigh, Trofimova, 2016; Kuimova, Karpacheva, 2016]. Reading in the target language provides context and fosters reading habits, allows seeing the language in use, deepens cultural knowledge [Sheu, 2004; Horst, 2005; Lai, 2013; I-Chin Nonie Chiang, 2015; Şen, Kuleli, 2015; Ölmez, 2015]. Reading increases learning motivation 
and enhances vocabulary and grammar achievements [Pigada, Schmitt, 2006; Alzu'bi, 2013; Wang, 2013; Pietilä, Merikivi 2014]. Many educators note that reading is rewarding and stimulating for both students and teachers. It:

- stimulates interests and sparks imagination;

- widens world view;

- forms a positive attitude towards the country and people of the target language and provides a greater insight into human nature;

- improves students' confidence in real situations [Rezaee, Nourzadeh, 2011; Yoğurtçu, 2013].

Reading enhances the ability to think, improves writing and speaking skills, increases students' knowledge of the history and culture of another country, contributes to personal growth and psychological development [Li, 2015; Abdulmughni, 2016; Kuimova, Zvekov, 2016].

\section{Discussion and research}

In a variety of real-life situations, we turn to the literature heroes who help and shape us, awakening our inner voice - the voice of conscience and reflection. Reading creates verbal conditions for active work on oneself. Literature often revolves around life and non-standard situations, stimulating interest, the search for self-responses, assumptions and guesswork. Extracurricular reading activities should be encouraged by teachers and linked with the curriculum of the course. They should be regular and consistent with the students' age, interests and background knowledge.

Reading performs cognitive, aesthetic and moral functions. It is a means of mental, moral and aesthetic education. To turn reading into an interesting and valuable activity, a teacher should select texts taking into account the following:

- topicality and novelty of the information;

- correspondence to the educational objectives;

- suitability to the students' linguistic competence (they must be readable and accessible to students);

- age-appropriateness;

- relevance to the students' interests and needs;

- skills that need to be practiced:

a) skimming for the essential meaning;

b) scanning for key details;

c) intensive reading (attention to discourse markers, grammatical forms, etc.);

d) extensive (e.g. reading for pleasure).

Teacher should further students' love for reading and learning the language. The types of work with the texts are equally important to the selection of materials. Generally, the tasks divide into:

- pre-reading;

- while-reading;

- post-reading.

Pre-reading tasks aim at modeling the background knowledge needed to eliminate notional and language difficulties and working out a "strategy of comprehension". For example,

- read the title and tell what the text will be about;

- read the passage and find the words which mean ...; 
- explain the meaning of the bold words using the context;

- read the passage and find the words proving that this is about ...;

- look through the text and identify its character (description, reasoning, narration);

- read the passage and find the sentence with the estimation of the behavior of the character/appearance. Pay attention to similes/epithets/metaphors;

- read the text till the indicated space. Tell your opinion how the event will finish.

While-reading tasks aim at communicative orientation, intending to instruct on the type of reading (skimming, scanning, intensive or extensive). For example,

- read the text and enumerate questions that are covered in it;

- read the text and place the plan items according to the logic of the narration;

- choose the annotation that best meets the content of the text;

- read the text and tell into how many parts it can be divided;

- mention facts from the text that prove/disprove the following ...;

- read the final passage. Tell what content could precede it;

- look through the text and tell for what category of readers it can be interesting.

Post-reading tasks aim at checking the comprehension of the read text and possible creative use of the information. For example,

- tell what title can be given to the text. Illustrate your point of view;

- tell facts/data that you first learned from the text;

- arrange the following questions in the sequence that corresponds to the content of the text;

- prove the author's standpoint in the text using your own example;

- comment on the following statements taken from the text;

- explain the following image to the text;

- tell where you can use the obtained information from the text.

In addition, to bring entertainment and creativity to the class, the following post-reading activities can be used:

- role-games;

- interviews;

- dramatization;

- quizzes;

- group discussions;

- debates;

- musical performances;

- essays, etc.

To study the effects of extracurricular reading, we took two groups: experimental and control. Each group consisted of 17 students studying at the second course of the Institute of Non-Destructive Testing, National Research Tomsk Polytechnic University. Once in two weeks the students of the experimental group were given extracurricular reading during the entire semester. At the end of the semester, the students of the experimental group showed better results in the final achievement test. In addition, students noted that extracurricular reading helped to decrease foreign language reading anxiety, fear of new vocabulary and unknown grammar, improved confidence in reading performance tests.

To encourage students' reading motivation, a teacher should not only organize the work with reading, but also encourage students' active work by giving additional grades, various rewards, prizes, praise and respect. 


\section{Conclusion}

Thus, reading often revolves around non-standard life and professional situations. It complements the curriculum, helps to perform well at studies, promotes cultural awareness and enriches students' knowledge of the language. While reading, students gain extensive background knowledge, which helps understand the mentality of the target language countries, develops communicative competence and expands cultural horizons.

\section{References}

1. Chen, M.-L. Teaching English as a foreign language through literature // Theory and Practice in Language Studies, Volume 4, Issue 2, 2014, pp. 232-236.

2. Kuimova, M., Burleigh, D. \& Trofimova, A. Problem-based teaching in engineering education // MATEC Web of Conferences, Volume 48, 2016, DOI http://dx.doi.org/10.1051/matecconf/20164806006.

3. Kuimova, M.V. \& Karpacheva, E.V. Game as a Means to Enhance Foreign Language Teaching // Ponte, Volume 72, Issue 2, 2016, pp. 14-17.

4. Sheu, P.H. The effects of extensive reading on learners' reading ability development // Journal of National Taipei Teachers College, 2004, Volume 17, Issue 2, pp. 213-228.

5. Horst, M. Learning L2 vocabulary through extensive reading: A measurement study // The Canadian Modern Language Review, Volume 61, Issue 3, 2005. pp. 355-382.

6. Lai, H.-Y.T. Learning English as an international language: EFL learners' perceptions of cultural knowledge acquisition in the English classroom // Asian Social Science, Volume 10, Issue 1, 2013, pp. 1-11.

7. I-Chin Nonie Chiang. A New Interpretation of English Reading Activities: The Implementation of the Principles of Deep Knowledge // International Journal of Language and Linguistics, Volume 2, Issue 4, 2015, pp. 152-161.

8. Şen, Yu. \& Kuleli, M. The Effect of Vocabulary Size and Vocabulary Depth on Reading in EFL Context // Procedia - Social and Behavioral Sciences, Volume 199, 2015, pp. $555-562$.

9. Ölmez, F. An Investigation into the Relationship Between L2 Reading Motivation and Reading Achievement // Procedia - Social and Behavioral Sciences, Volume 199, 2015, pp. 597-603.

10. Pigada, M. \& Schmitt, N. Vocabulary acquisition from extensive reading: a case study // Reading in a Foreign Language, Volume 18, Issue 1, 2006, pp. 1-28.

11. Alzu'bi, M.A. The effects of an extensive reading program on improving English as foreign language proficiency in university level education // English Language Teaching, Volume 7, Issue 1, 2013, pp. 28-35.

12. Wang, Y.-H. Incidental vocabulary learning through extensive reading: A case of lower-level EFL Taiwanese learners // Journal of Asia TEFL, Volume 10, Issue 3, 2013, pp. 59-80.

13. Pietilä, P. \& Merikivi, R. The impact of free-time reading on foreign language vocabulary development // Journal of Language Teaching and Research, Volume 5, Issue 1, 2014, pp. 28-36.

14. Rezaee, A.A. \& Nourzadeh, S. Does Extensive Reading Improve EFL learners' Processing Ability? // Theory and Practice in Language Studies, Volume 1, Issue 9, 2011. pp. 1167-1175.

15. Yoğurtçu, K. The Impact of Self-efficacy Perception on Reading Comprehension on Academic Achievement // Procedia - Social and Behavioral Sciences, Volume 70, 2013, pp. 


\section{$375-386$.}

16. Li, Z. Connecting reading and writing: A case study // English Language Teaching, Volume 8, Issue 6, 2015, pp. 150-158.

17. Abdulmughni, S.A.S. Teaching skills through literature // International Journal of Applied Linguistics and English Literature, Volume 5, Issue 2, 2016, pp. 10-16.

18. Kuimova, M.V. \& Zvekov, O.D. Blogs as a Means to Enhance Writing Skills in EFL Classes // International Journal of Emerging Technologies in Learning, Volume 11, Issue 4, 2016, pp. 157-160. 